\title{
ANIONIC POLYELECTROLYTE-CATIONIC SURFACTANT INTERACTIONS IN AQUEOUS SOLUTIONS AND FOAM FILMS STABILITY
}

\section{A. ASNACIOS}

Institut Curie'

\section{BERGERON}

Rhône-Poulenc 2

\section{LANGEVIN}

Centre de Recherche Paul Pascal ${ }^{3}$

\section{J.-F. ARGILLIER}

Institut français du pétrole 4

\section{INTERACTIONS ENTRE POLYÉLECTROLYTES ANIONIQUES ET TENSIOACTIFS CATIONIQUES EN SOLUTIONS AQUEUSES ET STABILITÉ DES FILMS DE MOUSSES}

L'objectif de cette étude est d'étudier les interactions polymère/ tensioactif en solution aqueuse et à l'interface eau/air. Ces interactions interviennent dans de nombreux phénomènes physicochimiques tels que la stabilisation de suspensions colloïdales et la mouillabilité qui sont d'une importance majeure dans les applications pétrolières comme, par exemple, les boues de forage.

Plus précisément, nous avons essayé de caractériser les interactions entre un copolymère anionique n'ayant pas d'activité de surface (acrylamide/acrylamide sulfoné) avec un tensioactif de charge opposée cationique $\left(\mathrm{C}_{12} T A B\right)$. Nos résultats montrent une diminution synergique de la tension superficielle (coadsorption) à des concentrations en tensioactifs très faibles $\left(10^{-3}\right.$ à $\left.10^{-1} \mathrm{CMC}\right)$. $A$ plus fortes concentrations, en particulier supérieures à la concentration critique d'agrégation (CAC), des complexes polymères/tensioactifs se forment en solution et les macromolécules précipitent. Les films minces réalisés à partir de ces solutions sont stables, alors que les films $\mathrm{C}_{12} \mathrm{TAB}$ sont instables.

Les mesures de pression de disjonction sur des films mixtes avec des concentrations en tensioactifs de deux ordres de grandeur en dessous de la CAC montrent l'existence de forces de répulsion à longue portée et une transition discrète d'épaisseur du film. À la valeur de la CAC, nous obtenons des films mixtes avec des réseaux similaires à un gel qui sont fortement affectés par la vitesse d'amincissement du film.

ANIONIC POLYELECTROLYTE-CATIONIC SURFACTANT INTERACTIONS IN AQUEOUS SOLUTIONS AND FOAM FILMS STABILITY

The objective of this work is to study polymer/surfactant interactions in aqueous solution and at the air/water interface. These interations are involved in many physicochemical phenomena, such as colioidal stabilization and wettability which are of major importance in oil application as for exemple driling muds.

More precisely, we have attempted to characterize interactions between a non surface active anionic copolymer (acrylamide/acrylamide sulfonate) and an oppositely charged cationic surfactant $\left(C_{12} T A B\right)$. Our results show a synergestic surface tension lowering (coadsorption) at extremely low surfactant concentrations $\left(10^{-3}\right.$ to $10^{-1} \mathrm{CMC}$ ). At higher concentrations, namely above the so called Critical Aggregation Concentration (CAC), polymer-surfactant com- 
plexes form in the bulk and the macromolecules precipitate out of the solution. Foam films made from these mixed solutions are stable while $\mathrm{C}_{12}$ TAB films are unstable.

Disjoining pressure measurements on mixed films with surfactant concentration two orders of magnitude below the CAC show the existence of long range repulsive forces and a discrete film thickness transition. At the CAC, we obtain mixed films with gel-like networks that are strongly affected by the film thinning rate.

INTERACCIONES ENTRE POLIELECTROLITOS ANIÓNICOS Y TENSIOACTIVOS CATIÓNICOS EN SOLUCIONES ACUOSAS Y ESTABILIDAD DE LAS PELÍCULAS DE ESPUMA

El objetivo del presente estudio consiste en estudiar las interacciones polimero tensioactivo en la interfaz agua/aire. Estas interacciones intervienen en numerosos fenómenos fisicoquímicos como por ejemplo, la estabilización le las suspensiones coloidales y la humectabilidad que presentan una gran importancia en las aplicaciones petroleras, como por ejemplo, los lodos de perforación.

Habida cuenta de que la adición de un copolímero aniónico no ejerce ninguna actividad de superficie (acrilamida/acrilamida sulfonado) con una solución de tensioactivo de $\mathrm{C}_{12}$ TAB $\left(10^{-3}\right.$ a $10^{-1}$ $\mathrm{CMC}$ ), da lugar a una adsorción sinérgica de dos especies de interfaz aire/agua. Las películas de bajo espesor realizadas a partir de estas soluciones son estables mientras que las películas $\mathrm{C}_{12}$ TAB son inestables.

Las mediciones de presión de disyunción efectuadas mediante películas mixtas con concentraciones de tensioactivo de dos órdenes de magnitud por debajo de la Concentración de Agregación Crítica (CAC) vienen a demostrar la inexistencia de fuerzas de repulsión de largo alcance y una transición discreta de espesor de la película. Con el valor de la CAC, obtenemos películas mixtas con redes similares de gel. Estas estructuras de gel son sensibles a la velocidad de formación de la película, pero no se encuentran afectadas por el adelgazamiento de la película.

\section{MATERIALS}

The cationic surfactant, dodecyl trimethyl ammonium bromide $\left(\mathrm{C}_{12} \mathrm{TAB}\right)$ from Aldrich $(99 \%)$, was recrystallized ( $2 \mathrm{~g} \mathrm{C}_{12}$ TAB: $10 \mathrm{ml}$ ethyl acetate: $1 \mathrm{ml}$ ethyl alcohol) 3 times before use. No minimum in the surface tension versus surfactant concentration was observed after purification.

The polyelectrolyte used is a random-block copolymer of acrylamide (AM) and acrylamido methyl propane sulfonate (AMPS) synthetized by $S N F$ Floerger that we will named AAS. The samples were composed of $75 \mathrm{~mol} \%$ of neutral AM and $25 \mathrm{~mol} \%$ of charged AMPS monomers. The polymer's chemical structure has been characterized by titration via a bromidation reaction for the amide function and potentiometric titration for the sulfonate group. The molecular weight and polydispersity of the polymer were measured by size exclusion chromatography (SEC) coupled with multiangle light scattering, which gave $\mathrm{M}_{\mathrm{w}}=2.810^{6}$ and $\mathrm{M}_{\mathrm{w}} / \mathrm{M}_{\mathrm{n}}=1.5$. In $\mathrm{NaCl} 1 \mathrm{~g} / \mathrm{l}$, the average radius of the polymer chains is $R_{\mathrm{w}}=110 \mathrm{~nm}$. To eliminate any traces of surfactant molecules and/or low molecular weight impurities, the polymer solutions were passed through an ultrafiltration unit with a 20.000 cut-off membrane. Final concentrations were determined using a total carbon analyser Shimatzu TOC 5050. After this purification, the polymer displays no surface activity at concentrations below $2000 \mathrm{ppm}$. Detailed descriptions and references concerning the experimental techniques and methods can be found in [1] and [9].

\section{RESULTS}

\subsection{Properties of bulk solutions}

\subsubsection{Surface Tension}

We have studied the changes induced by the presence of a fixed amount of AAS copolymer on the surface tension isotherm of the $\mathrm{C}_{12} \mathrm{TAB}$. Figure 1 displays the surface tension isotherms (surface tension versus surfactant concentration) with and without $750 \mathrm{ppm}$ added copolymer. The comparison of the two curves reveals that the mixed solutions show a synergistic lowering of surface tension at very low surfactant concentrations. Note that the AAS copolymer alone is not surface active [1]. The surface tension isotherm of the mixed 
solutions exhibits two plateaus identified by two characteristic break points in the isotherm. The first, known as the Critical Agregation Concentration (CAC), corresponds to the begining of a significant number of polymer/surfactant complexes in the bulk, while the second corresponds to the $\mathrm{CMC}$ of polymer-free $\mathrm{C}_{12} \mathrm{TAB}$. The coincidence between the surface tension curves with and without polymer for concentrations of $\mathrm{C}_{12} \mathrm{TAB}$ above $9 \mathrm{mM}$ arises from the fact that all of the polymer has precipitated out of the solution at this point, leaving an essential pure surfactant solution.

Figure 1 also indicates that at low surfactant concentrations $\left(10^{-5} \mathrm{M} \mathrm{C}_{12} \mathrm{TAB}\right)$, the surface activity of the surfactant is negligible, yet there is a substantial lowering of the surface tension when the (non surface active) polymer is present. This effect implies coadsorption of AAS and $\mathrm{C}_{12} \mathrm{TAB}$ molecules at the air/solution interface and formation of a highly surface active polymer/surfactant complex.

\subsubsection{Bulk Viscosity}

Additonal information concerning the $\mathrm{C}_{12} \mathrm{TAB}-\mathrm{AAS}$ interactions can also be obtained from bulk viscosity measurements. Thus, in Figure 2, we plot the bulk viscosity (normalised by its value for a $750 \mathrm{ppm}$ AAS solution) for $750 \mathrm{ppm}$ AAS-C $\mathrm{C}_{12} \mathrm{TAB}$ and $750 \mathrm{ppm}$ AAS- $\mathrm{KBr}$ solutions versus $\mathrm{C}_{12} \mathrm{TAB}$ or $\mathrm{KBr}$ concentration. As can be seen in Figure 2, for $\mathrm{C}_{12} \mathrm{TAB}$ concentrations below the $\mathrm{CAC}$, the decrease in viscosity with added surfactant is identical to that of added $\mathrm{KBr}$. However, above the $\mathrm{CAC}, \mathrm{C}_{12} \mathrm{TAB}$ has a much stronger effect than $\mathrm{KBr}$. In fact, slightly above the $\mathrm{CAC}$, the $\mathrm{AAS}-\mathrm{C}_{12} \mathrm{TAB}$ mixed solutions become turbid, we observe a white precipitate and the measured viscosities correspond to that of pure water (we actually find the same value for pure $\mathrm{C}_{12} \mathrm{TAB}$ solutions).

These observations indicate that, below the CAC, $\mathrm{C}_{12} \mathrm{TAB}$ is completely dissociated and behaves as a simple salt. That is, the increased ionic strength upon addition of surfactant or simple electrolyte screens the electrostatic repulsions between charged groups on the polymer backbone, leading to smaller hydrodynamic volumes and lower relative viscosities. However, at the CAC, the surfactant concentration is high enough to form (in the bulk!) tightly packed polymer-surfactant complexes that eventually precipitate out of the solution to form a separate phase. This precipitation of the macromolecules is consistent with the coincidence between the surface tension curves with and without polymer for $\mathrm{C}_{12} \mathrm{TAB}$ concentrations above $9 \mathrm{mM}$.

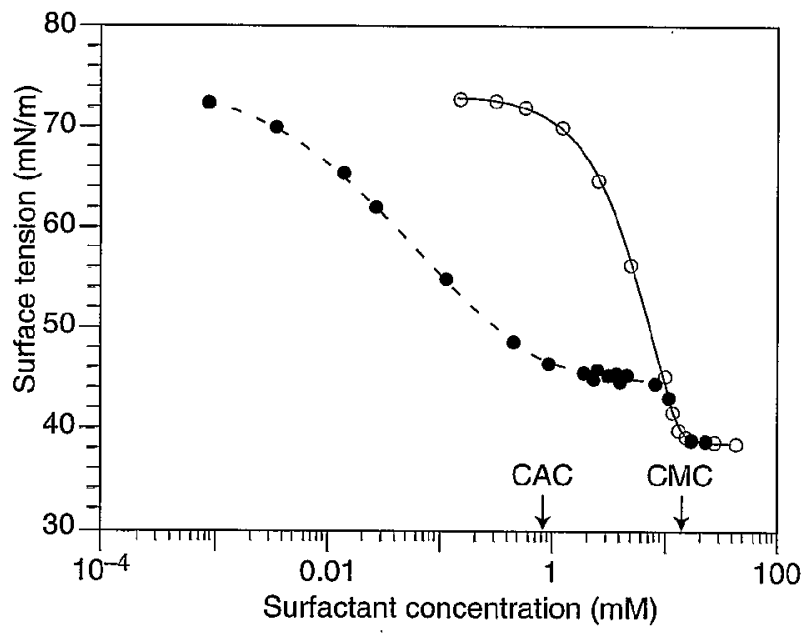

Figure 1

Effect of AAS copolymer on $\mathrm{C}_{12}$ TAB surface tension: (O) $\left.\mathrm{C}_{12} \mathrm{TAB} ; \bullet\right) \mathrm{C}_{12} \mathrm{TAB}+750 \mathrm{ppm}$ of AAS.

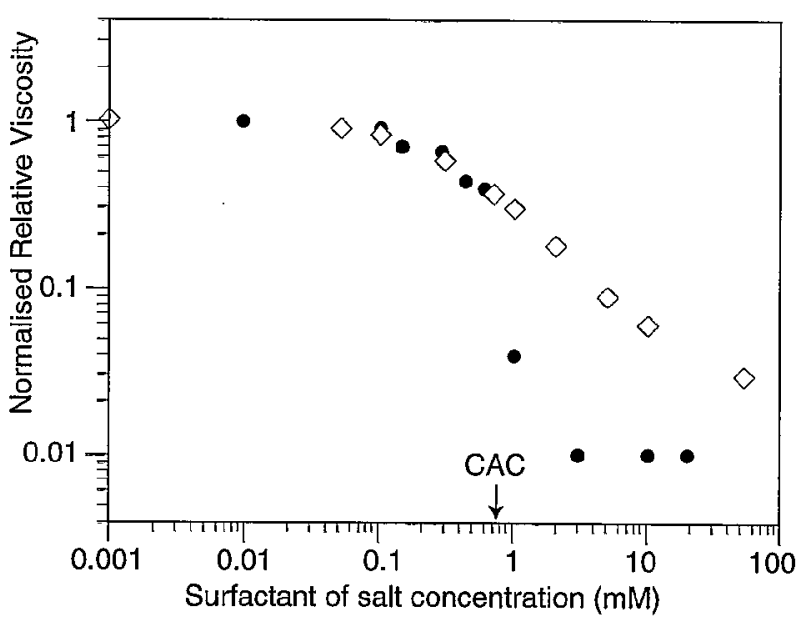

Figure 2

Comparison of the effect of $C_{12} T A B$ and salt on the relative viscosity of a $750 \mathrm{ppm}$ solution of AAS: ( $\mathrm{AAS} / \mathrm{C}_{12} \mathrm{TAB}$; $(\diamond) \mathrm{AAS} / \mathrm{KBr}$

In summary, below the CAC, while there is no complexation between the polymer and the surfactant in the bulk, the two species coadsob at the solution/air interface to form a highly surface active complex. Above the CAC, complexation occurs in bulk, the polymer molecules precipitate out and the mixtures finally recover the surface tension and viscosity of the polymer-free surfactant solutions. 


\subsubsection{Ellipsometry}

Ellipsometric measurements allow us to determine the thickness of the adsorbed mixed layer. We find that the layer properties are also very dependent on the surfactant concentration. Again, the CAC appears as the limit between two different regimes. Below the CAC, one finds homogeneous thin layers with thicknesses between 1 and $6 \mathrm{~nm}$ that suggest a flat polymer conformation. Above the $\mathrm{CAC}$, the adsorbed layer becomes heterogeneous and thicker. The surface layer is then formed of domains of different thicknesses ranging from 40 to $80 \mathrm{~nm}$. More information and details concerning these results (including a thermodynamic analysis) can be found in [1] and [2].

\subsection{Properties of foam films made from mixed solutions. Disjoining pressure isotherms}

We have studied foam films at two characteristic $\mathrm{C}_{12} \mathrm{TAB}$ concentrations: 0.05 and $1 \mathrm{mM}$, which are respectively below and slightly above the CAC. We note that foam films made from $\mathrm{C}_{12} \mathrm{TAB}$ alone at these concentrations are completely unstable and we are unable to determine the disjoining pressure isotherms for the pure surfactant solutions.

\subsubsection{Below the CAC}

Figure 3 displays the disjoining pressure isotherm for a $0.05 \mathrm{mM} \mathrm{C}_{12} \mathrm{TAB}$ solution with $750 \mathrm{ppm}$ added AAS copolymer. This isotherm contains two repulsive branches which we accentuate further by sketching in lines between the data points. The first branch is encountered at rather thick films, $h \approx 125 \mathrm{~nm}$, and is stable until pressures near $500 \mathrm{~Pa}$ are reached. Imposing a higher pressure results in a discrete transition to a new metastable equilibrium thickness of about $75 \mathrm{~nm}$. The transition process is pictured in Figure 4, where the lightly colored region corresponds to a film thickness of $125 \mathrm{~nm}$ and the darker (grey) expanding portion is the thinner $75 \mathrm{~nm}$ region which eventually covers the entire film. In thin-liquid films this type of transition is termed "film stratification" [3]. Both of the repulsive branches of the isotherm are reproducible, and hysteresis along a branch upon lowering the imposed pressure is not observed. Finally, once the pressure exceeds $1000 \mathrm{~Pa}$ the film ruptures.

The film stratification observed in Figure 3 is quite striking because it is the first observation of this phenomenon in foam films made from solutions well below the CMC, and also below the CAC! All previous observations have been made in highly concentrated surfactant solutions or in solutions containing microscopic particles $[3,4,5,6,7]$. In these cases stratification is due to supramolecular structuring of the surfactant aggregates (i.e. micelles or bilayers) or of the micoscopic particules in the films. However, our mixed solutions are very dilute in both surfactant and polymer, and it is unlikely that the present stratification arises from the structuring of micelles, lamella or mixed aggregates. Thus, we have first suggested that this stratification could be due to bridging between the two adsorbed layers [8]. Another possibility is that the distance between branches might be related to the mesh size $\xi$ of the temporary netowrk formed by the macromolecules in a semi-dilute regime [9]. In this regime, the macromolecules can be seen as ideal chains of rods of size $\xi$, and rods are uncorrelated in orientation [11]. An estimation of the overlap concentration c* clearely show that our systeme is in the semi-dilute regime [2].

Recent observations show that the number of branches increases and the inter-branche distance decreases with increasing polymer concentration [10]. This behaviour is in agreement with the correlation length $\xi$ dependence on polyelectrolyte concentration.

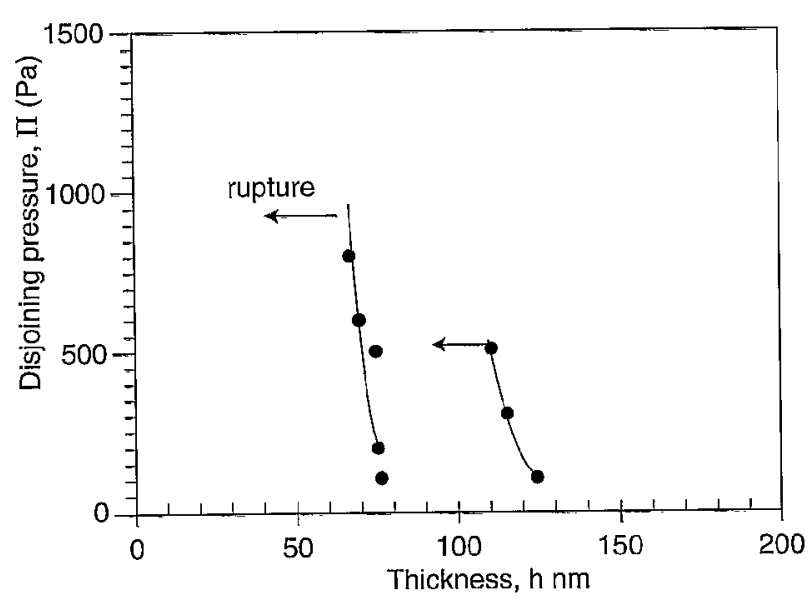

Figure 3

Disjoining pressure isotherm for foam films formed from a mixed solution containing $0.05 \mathrm{mM} \mathrm{C}_{12} \mathrm{TAB}$ and $750 \mathrm{ppm}$ AAS. 

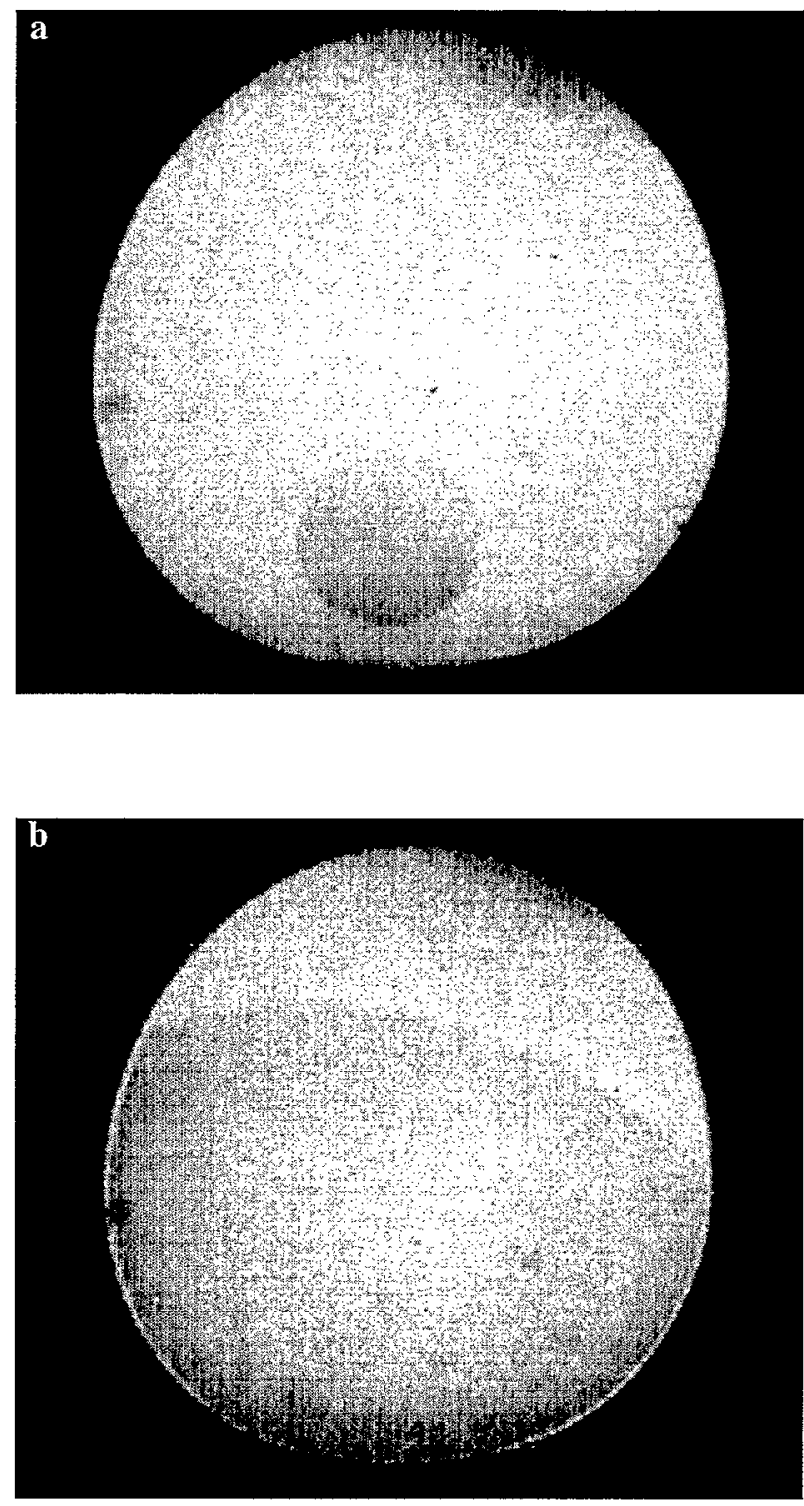

Figure 4

Stratification event for a foam film formed from a mixed solution containing $0.05 \mathrm{mM} \mathrm{C}_{12} \mathrm{TAB}$ and $750 \mathrm{ppm}$ AAS.

The important characteristic of semi-dilute polyelectrolyte solutions is that the correlation length $\xi$, the inter-rod distance $d$ and the Debye length $\lambda$ are of the same order [11]. There is a strong electrostatic repulsion at distances smaller than $\xi$, and the structure factor shows a peak at a wavevector $\mathrm{q}^{*} \approx 1 / \xi$. Thus, the distance between branches is probably on the order of $\xi$.
One can casily imagine that the macromolecules (behaving as a succession of sub-units of length $\xi$ uncorrelated in their orientation) can adjust their conformations to stay in a film of a thickness of only a few times $\xi$. Moreover, it is worth noting that the viscosity behaviour of our solutions implies that the polyelectrolyte molecules, even in the semi-dilute regime, are not entangled enough to show a reptation dynamic [2]. This implies that molecules can be easiliy squeezed out of the film at cach transition, allowing the remaining ones to flatten themselves to satisfy the constraint of a film thickness $\xi$ smaller. The whole process is then equivalent to having a film formed of a close packing of spheres of size $\xi$, a layer of such spheres being squeezed out at each thickness transition.

\subsubsection{Above the CAC}

Mixed solutions at $750 \mathrm{ppm}$ of AAS copolymer and $1 \mathrm{mM} \mathrm{C}_{12}$ TAB produces films with a quite different behavior than that seen at the lower $\mathrm{C}_{12} \mathrm{TAB}$ concentration. In this case, the film thickness becomes very heterogeneous. This phenomenon is pictured in the series of photos shown in Figure 5. These images are taken from a VCR recording of the film and correspond to observations made with a color CCD camera mounted on the microscope. All four images are from the same film but correspond to different imposed pressures. The series begin with Figure 5a at an imposed pressure of approximately $50 \mathrm{~Pa}$ followed by progressively higher pressures (Figure 5d, P > $5000 \mathrm{~Pa}$ ). As can be easily seen, the film pictured in Figure 5 is thick enough to produce iridescent colors from thin-film interference under white light illumination. Each color corresponds to a different film thickness and it is evident that the thickness is highly heterogeneous across the film. In fact, there are two types of heterogeneities: microscopic, on the order of $20 \mathrm{~mm}$ diameter, which appear as spots scattered throughout the film, and much larger irregularly shaped macroscopic domains. The microscopic spots corresponds to regions of about $1 \mathrm{~mm}$ thickness, while macroscopic domains have thicknesses of 100-200 nm. From the photos in Figure 5, it can also be observed that, as the pressure is increased, each macroscopic domain becomes thinner (as evident by the changes in color), yet the shape integrity of the domains remains intact. Finally, pronounced hysteresis of the film thickness behaviour is observed when the pressure is lowered. 
The fact that the spots located in the film and the macroscopic domain shapes are unaffected by the overall thinning of the film under pressure increases suggests the existence of a gel-like network within the foam films made from mixed solutions with surfactant concentration above the CAC. It is interesting to note that the macroscopic domain thicknesses correspond quite well to twice the adsorbed layer thickness measured by ellipsometry at the air/solution interface. Moreover, since polymer-surfactant complex formation in the bulk begins at the CAC, one can imagine that micro-gel domains appear in the bulk solutions at this concentration and that such micro-gels can be adsorbed at the air/water interface The presence of such a gellike network is not surprising as we have observed white rubber-like aggregates in the bulk solution after the CAC. It is in fact worth noting that the gel-like films have a very long relaxation times (the imposed pressure on the film can be held constant for days without observing any significant change in the heterogeneous thickness profile). More details concerning these gel like films can be found in [2] and [8].

\section{CONCLUSIONS}

Oppositely charged AAS polyelectrolyte and $\mathrm{C}_{12} \mathrm{TAB}$ surfactant interact strongly in aquous solution. They form complexes in the bulk solution as well as at the air/water interface, and $\mathrm{C}_{12} \mathrm{TAB}$ thin films can be stabilized by the addition of AAS. At fixed polymer concentration, both bulk, interfacial and film properties change dramatically with the surfactant concentration. One can essentially distinguish two different regimes:

- Well below the critical aggregation concentration (CAC $<\mathrm{CMC}$ ), while there is no complexation in the bulk, the polymer and the surfactant coadsorb at the air/water interface producing a synergestic surface tension lowering. The adsorbed layer is then homogeneous and thin $(<6 \mathrm{~nm})$ indicating a flat polymer conformation at the interface. Mixed films at these extremely low sufactant and polymer concentrations show discrete thickness transitions probably due to polyelectrolyte structuration in the films.

- Slightly above the CAC, polymer-surfactant complexation occurs in bulk and the macromolecules precipitate out (forming white rubber-like aggregates). The adsorbed mixed layer then has a thick and heterogeneous profile $(>40 \mathrm{~nm})$. Finally, mixed films exhibit a gel-like structure with heterogeneous thicknesses.

\section{REFERENCES}

1 Asnacios A., D. Langevin and J.F. Argillier (1996), Macromolecules, 29, pp. 7412-7417.

2 Asnacios A. (1997), Thesis, Paris.

3 Bergeron V. and C.J. Radke (1992), Langmuir, 8, p. 3020.

4 Exerowa D. and Z. Lalchev (1986), Langmuir, 2, p. 668.

5 Richetti P. and P. Kékicheff (1992), Phys. Rev. Letters, 68, 12, pp. 1951-1954.

6 Nikolov A. and D.T. Wasan (1992), Langmuir, 8, p. 2985.

7 Bergeron V. and C.J. Radke (1995), Colloid. Polym. Sci., 273 , p. 165.

8 Bergeron V., D. Langevin and A. Asnacios (1996), Langmuir, 12, 6, pp. 1550-1556.

9 de Gennes P.G., P. Pincus, R.M. Velasco, and F. Brochard (1976), Journal de Physique, 37, pp. 1461-1473.

10 Asnacios A., A. Espert, A. Colin and D. Langevin, submitted for publication in $P R L$.

11 Barrat J.L. and J.F. Joanny (1996), Adv. Chem. Phys., 94, p. 1.

Manuscript received in January 1997 

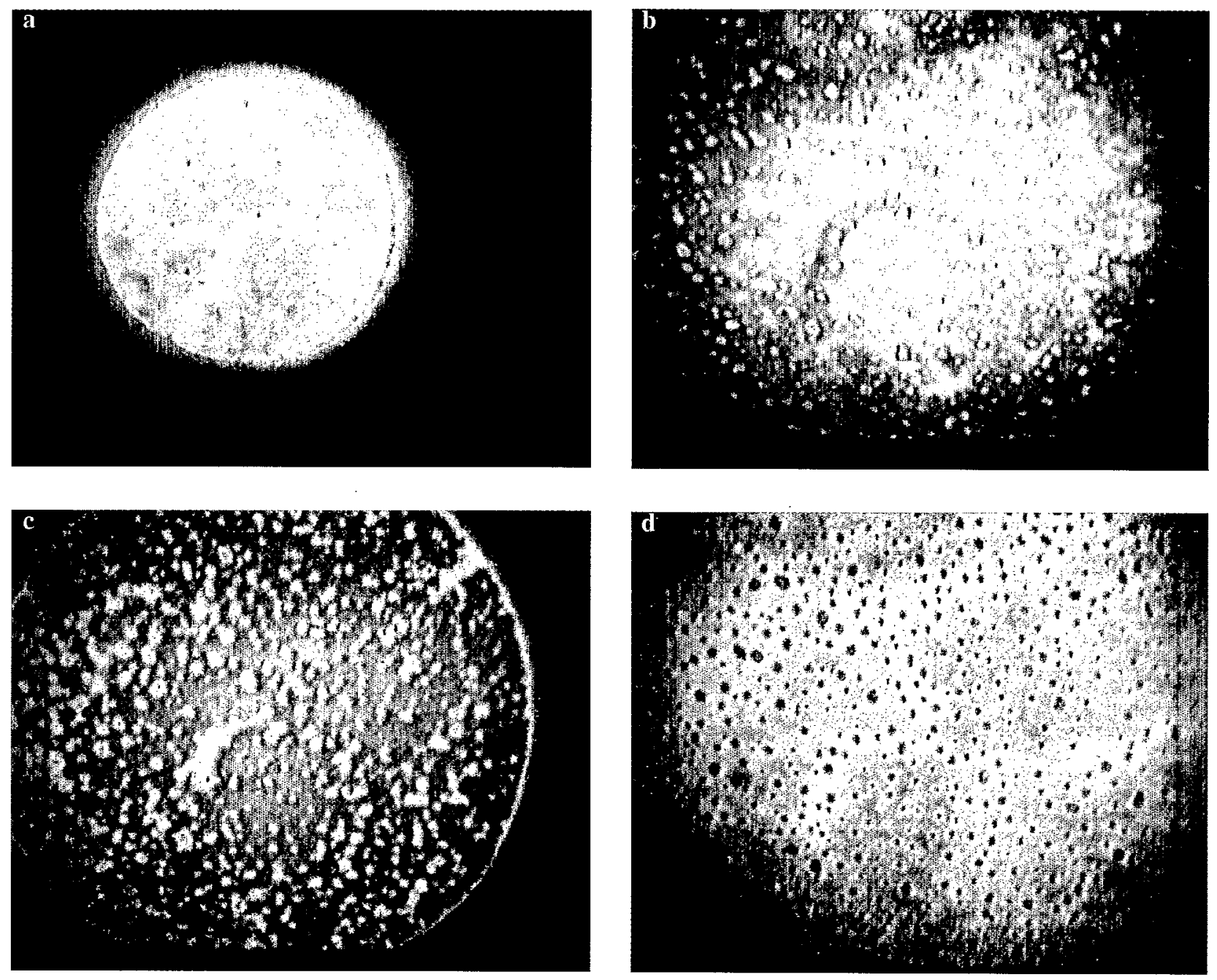

Figure 5

Sequence of photos taken from a single foam film formed from a mixed solution containing $1 \mathrm{mM} \mathrm{C}_{12} \mathrm{TAB}$ and $750 \mathrm{ppm}$ AAS copolymer. Each frame corresponds to a different imposed pressure on the film: (a) $50 \mathrm{~Pa}$; (b) $250 \mathrm{~Pa}$; (c) $1000 \mathrm{~Pa}$; (d) $>5000 \mathrm{~Pa}$. 